\title{
Exercise, Antidepressant Medications, and Enhanced Brain Derived Neurotrophic Factor Expression
}

Amelia Russo-Neustadt, M.D., Ph.D., Ryan C. Beard, B.S., and Carl W. Cotman, Ph.D.

Physical activity and antidepressant treatment have each separately been of significant interest for the management of Alzheimer's disease (AD); particularly the behavioral problems associated with this dementing disorder. We have found that combined antidepressant treatment and physical activity have an additive, potentiating effect on BDNF $m R N A$ expression within several areas of the rat hippocampus. During the 20-day experimental period, animals were treated daily with imipramine $(15 \mathrm{mg} / \mathrm{kg})$ or tranylcypromine $(7.5 \mathrm{mg} / \mathrm{kg})$ by intraperitoneal injection. Exercising rat groups were given access to running wheels for the duration of the experiment. BDNF $m R N A$ levels were assessed in several cell groups of the hippocampus by in situ hybridization, using a $\left.{ }^{35} \mathrm{~S}\right]$ labelled riboprobe complementary to the full-length BDNF sequence, and computer-assisted densitometry. The combination of physical activity and antidepressant treatment for the 20day period led to a signifciant potentiation of full-length $B D N F m R N A$ levels within the dentate gyrus and CA 1, $C A 3$, and CA 4 cellular fields, above the levels obtained with each intervention alone. These results provide impetus for the study of physical exercise as a potential enhancer of treatment response to antidepressants.

[Neuropsychopharmacology 21:679-682, 1999] (C) 1999 American College of Neuropsychopharmacology. Published by Elsevier Science Inc.
KEY WORDS: Physical activity; BDNF; Growth factor; In situ hybridization; Monoamines; Behavior

In recent years, great strides have been made in understanding the regulation of growth factors at the molecular level. We report, for the first time, an apparent interaction between two distinct interventions, a pharmacological agent and a behavioral change, leading to a potentiation of brain-derived neurotrophic factor (BDNF) expression. As discussed below, this observation may have important applications to neurodegenerative/behavioral disorder treatment investigation and development.

From the Institute for Brain Aging and Dementia, University of California, Irvine, CA.

Address correspondence to: Amelia Russo-Neustadt, M.D., Ph.D., Institute for Brain Aging and Dementia, 1113 Gillespie Neuroscience Facility, University of California, Irvine, California 926974540 .

Received February 19, 1999; revised May 3, 1999; accepted May 11,1999
BDNF, the most widely distributed growth factor within the brain, has profound influences on the survival and function of several neurotransmitter systems. The expression of BDNF is responsive to a variety of stimuli which enhance neuronal activity (Boatell et al. 1992; Castrén et al. 1993; Gall 1993; Gwag and Springer 1993). In our Institute, general physical exercise has been shown to lead to rapid increases in rat hippocampal BDNF mRNA levels (Neeper et al. 1995, 1996), opening the possibility that this physiological behavior can lead to enhanced trophic support in key brain areas.

Alzheimer's disease (AD) is hallmarked by a decline in cognitive function, and in a majority of cases also by behavioral disturbances such as apathy, depression and aggression. BDNF expression is diminished in the brains of AD patients; specifically, within the hippocampus, a brain area known to have vital functions in learning and memory as well as in behavioral regulation (Phillips et al. 1991; Murray et al. 1994). Among the 
various pharmacological agents that have been used to treat the most problematic behavioral symptoms in dementia, antidepressants have shown particular promise (Aarsland 1995). The ultimate mechanism of these drugs is unknown, but recent reports have revealed an up-regulation of BDNF mRNA levels in the hippocampi of rats treated with a variety of antidepressant medications currently used in practice (Nibuya et al. 1995). We have tested the hypothesis that a combination of increased physical activity (voluntary wheel running) and the administration of antidepressant medications could lead to enhanced BDNF mRNA levels above those achieved with either intervention alone.

Rats were treated with one of two different antidepressant agents: tranylcypromine $(7.5 \mathrm{mg} / \mathrm{kg})$, a monoamine oxidase inhibitor, or imipramine $(15 \mathrm{mg} /$ $\mathrm{kg}$ ), a tricyclic antidepressant, via daily A.M. intraperitoneal injections (or saline vehicle) for a 20-day period.
In addition, specific groups of animals engaged in voluntary physical activity through free access to running wheels during the course of the experiment, and their activity levels were monitored by computer. Each of the six animal groups (treated with imipramine or tranylcypromine, with and without concomitant physical activity, and saline controls) contained seven animals. Active Sprague-Dawley rats ran an average of 2.1 kilometers per night, and running behavior was not significantly altered by drug treatment. Animals' weight diminished by an average of 3-5\% during the first few days of drug treatment, after which a general weight increase of approximately 3\% per week was resumed. Animals were sacrificed at 6:00 A.M. immediately following their final active period (and 21 hours after last drug treatment). This hour has been shown in previous experiments to be a point of peak circadian expression of BDNF (Berchtold et al. 1997). BDNF levels were as-
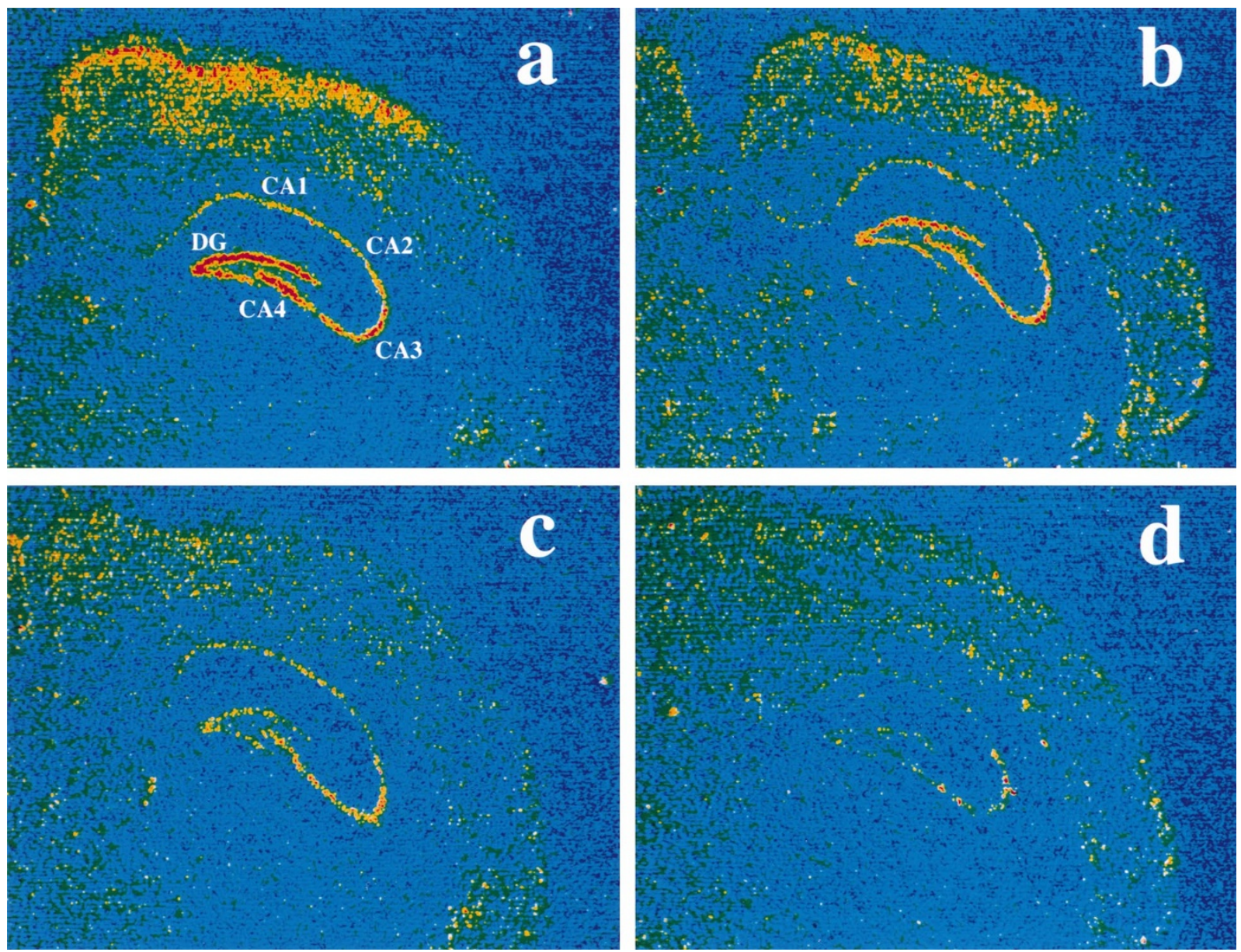

Figure 1. Color-enhanced image of autoradiograms from in situ BDNF mRNA hybridization in rat brain (coronal plane). Increasing hybridization (ROD) is represented by a rainbow scale (lowest to highest = blue, green, yellow, red). (a) The combination of activity \& antidepressant (tranylcypromine) $\times 20$ days. (b) Physical activity only (saline vehicle). (c) Tranylcypromine only (sedentary). (d) Control. The combination of physical activity and antidepressant administration led to additive increases in BDNF mRNA levels in several hippocampal cell fields (identified). DG= dentate gyrus. Methodological details can be obtained from the authors. 


\section{a Drug: Tranylcypromine}

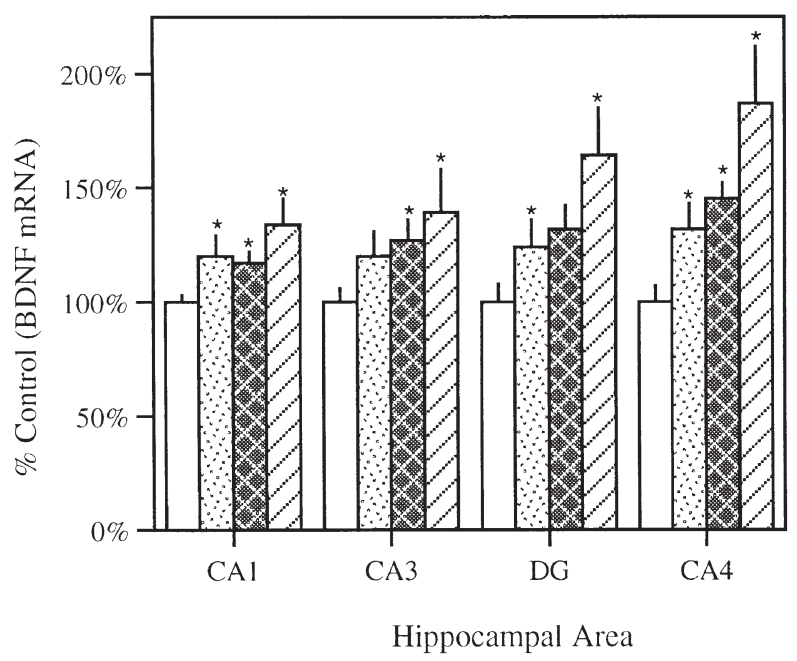

\author{
Treatment Group

$\square$ CTR
Antidepressant
$\square$ Activity
Antidepressant + Activity

\section{b Drug: Imipramine}

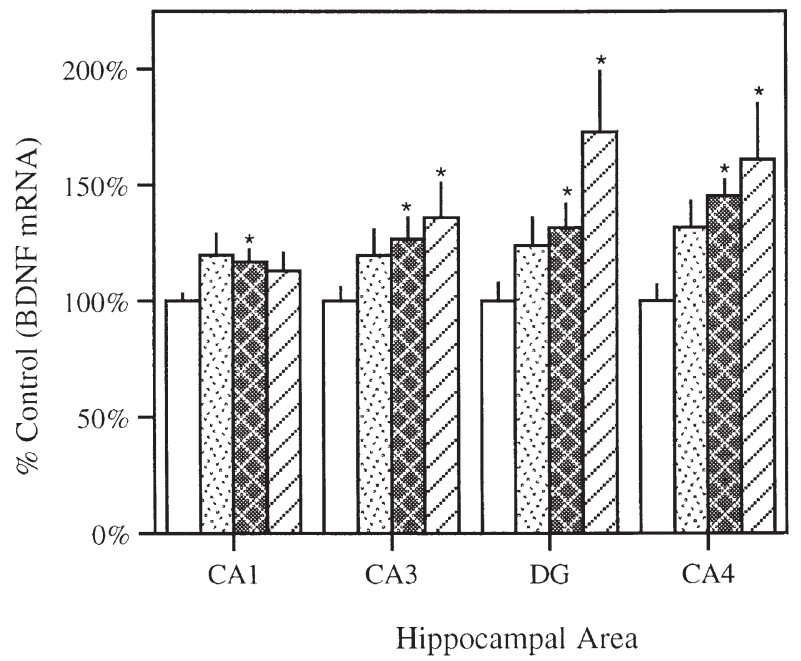

Figure 2. Quantification of antidepressant and activity-induced increases in BDNF mRNA in the rat hippocampus. (a) Physical activity or treatment with tranylcypromine alone caused significant increases in BNDF mRNA in several hippocampal cell fields. Additive increases were observed when drug treatment and activty were combined.(b) Treatment with imipramine alone did not significantly increase hippocampal BDNF mRNA levels. In contrast, the combination of imipramine treatment with activity led to significant increases in BDNF mRNA levels compared to controls, and also appeared to potentiate BDNF mRNA levels above those observed with activity alone (AI $>$ AS; $p=.08$ ).

sessed within the hippocampus via in situ hybridization, using a $\left.{ }^{35} \mathrm{~S}\right]$ labelled riboprobe complementary to the full-length BDNF sequence (Kindly provided by Dr. Paul Isackson), and computer-assisted densitometry. Autoradiographic images were calibrated relative to $\left[{ }^{14} \mathrm{C}\right]$ standards exposed together with the tissue to the film. Grain densities were measured in $7 \times 0.1 \mathrm{~mm}^{2}$ areas randomly selected from each hippocampal area, in each of three sections per animal, to determine silver grain density. Differences in BDNF mRNA levels between groups of animals were determined by two-way analysis of variance (ANOVA). Figure 1 displays autoradiographs of representative rat brain sections from four of these animal groups: Rats treated with tranylcypromine and saline controls, both in the presence and absence of concomitant physical activity (animals given access to running wheels, and sedentary animals with no wheels in their cages). The combination of antidepressant and physical activity led to a potentiation of
BDNF mRNA density in the hippocampus, above the level achieved with either intervention alone. The combined treatments led to increases in BDNF mRNA levels within Ammon's horn areas 1, 3 and 4 (CA 1, 3 and 4), as well as within the dentate gyrus (DG), with levels as much as $187 \%$ of controls (Figures 1 and 2). With activity and tranylcypromine, there was also a small increase in BDNF levels in the outer layers of the parietal association cortex (Figure 1). Potentiation of hippocampal BDNF mRNA levels by the treatment combination also occurred in situations where antidepressant alone appeared to have no significant effect (as was the case with imipramine-see Figure 2b).

Our findings indicate that physical activity, a simple, highly available and well-tolerated intervention, enhances the growth factor up-regulation resulting from antidepressant treatment. These results support the hypothesis that there is a common convergence point, at the cellular level, for the induction of BDNF expression 
by these two apparently disparate treatment approaches. Evidence exists that the enhancement of BDNF mRNA expression after antidepressant treatment is associated with increased expression of the transcription factor cAMP response element binding protein (CREB) in the rat hippocampus (Nibuya et al. 1996), evidenced to occur through cAMP, and that BDNF expression can also be regulated by activitystimulated calcium influx through a CREB-family dependent mechanism (Tao et al. 1998). Future studies may investigate whether antidepressant treatment and physical activity converge by both regulating BDNF through monoaminergic receptor activation, or whether one intervention (i.e., general physical activity) may activate the intracellular machinery through another mechanism, leading to a convergent effect through common or distinct transcription factors.

Evidence exists that physical activity and enhanced growth factor expression may be applied to the development of better behavioral treatments. Human clinical studies have shown improvements in psychiatric status, such as reduced depression and anxiety, and enhanced psychological capability for dealing with chronic stress, following long-term aerobic training (Hill et al. 1993; Labb et al. 1988). In addition, BDNF has been shown to modulate behavior in rats, and has been suggested to have antidepressant-like effects (Siuciak et al. 1997). The ultimate mehanism of antidepressants (as well as physical exercise) is still unclear, however, and has not been proven to occur through the regulation of BDNF. Still, as noted above, BDNF levels are known to be diminished in dementia. Our results provide evidence which stimulates investigation of the possibility that physical activity, in conjunction with antidepressant agents, could represent a novel treatment approach for the improvement of behavioral management in dementia.

\section{ACKNOWLEDGMENTS}

This work has been supported by U.S. Public Health Service Grant MH-01266.

\section{REFERENCES}

Aarsland D (1995): Aggressive behavior in dementia and its pharmacological treatment: A review. Nordisk J Psychiatry 49:111-118

Berchtold NC, Oliff HS, Isackson P, Cotman CW (1997): Brain-derived neurotrophic factor (BDNF) shows a cir- cadian pattern of expression in the hippocampal formation. Soc Neurosci Abstr 23:46

Boatell LL, Lindefors N, Ballarin M, Ernfors P, Mahy N, Persson H (1992): Activation of basal forebrain cholinergic neurons differentially regulates brain-derived neurotrophic factor mRNA expression in different projection areas. Neurosci Lett 136(2):203-208

Castrén E, Pitkänen M, Sirvio J, Parsadanian A, Lindholm D, Thoenen H, Riekkinen PJ (1993): The induction of LTP increases BDNF and NGF mRNA but decreases NT-3 mRNA in the dentate gyrus. Neuroreport 4(7):895-898

Gall CM (1993): Seizure-induced changes in neurotrophin expression: Implications for epilepsy. Exp Neurol 124(1):150-166

Gwag BJ, Springer JE (1993): Activation of NMDA receptors increases brain-derived neurotrophic factor (BDNF) mRNA expression in the hippocampal formation. Neuroreport 5(2):125-128

Hill RD, Storandt M, Malley M (1993): The impact of longterm exercise training on psychological function in older adults. J Gerontol 48(1):12-17

Labb EE, Welsh MC, Delaney D (1988): Effects of consistent aerobic exercise on the psychological functioning of women. Percept Mot Skills 67(3):919-925

Murray KD, Gall CM, Jones EG, Isackson PJ (1994): Differential regulation of brain-derived neurotrophic factor and type II calcium/calmodulin-dependent protein kinase messenger RNA expression in Alzheimer's disease. Neuroscience 60(1):37-48

Neeper SA, Gomez-Pinilla F, Choi J, Cotman C (1995): Exercise and brain neurotrophins [letter]. Nature 373(6510):109

Neeper SA, Gómez-Pinilla F, Choi J, Cotman CW (1996): Physical activity increases mRNA for brain-derived neurotrophic factor and nerve growth factor in rat brain. Brain Res 726(1-2):49-56

Nibuya M, Morinobu S, Duman RS (1995): Regulation of BDNF and trkB mRNA in rat brain by chronic electroconvulsive seizure and antidepressant drug treatments. J Neurosci 15(11):7539-7547

Nibuya M, Nestler EJ, Duman RS (1996): Chronic antidepressant administration increases the expression of cAMP response element binding protein (CREB) in rat hippocampus. J Neurosci 16(7):2365-2372

Phillips HS, Hains JM, Armanini M, Laramee GR, Johnson SA, Winslow JW (1991): BDNF mRNA is decreased in the hippocampus of individuals with Alzheimer's disease. Neuron 7(5):695-702

Siuciak JA, Lewis DR, Wiegand SJ, Lindsay RM (1997): Antidepressant-like effect of brain-derived neurotrophic factor (BDNF). Pharmacol Biochem Behav 56(1):131-137

Tao X, Finkbeiner S, Arnold DB, Shaywitz AJ, Greenberg ME (1998): Ca2+ influx regulates BDNF transcription by a CREB family transcription factor-dependent mechanism. Neuron 20(4):709-726 